
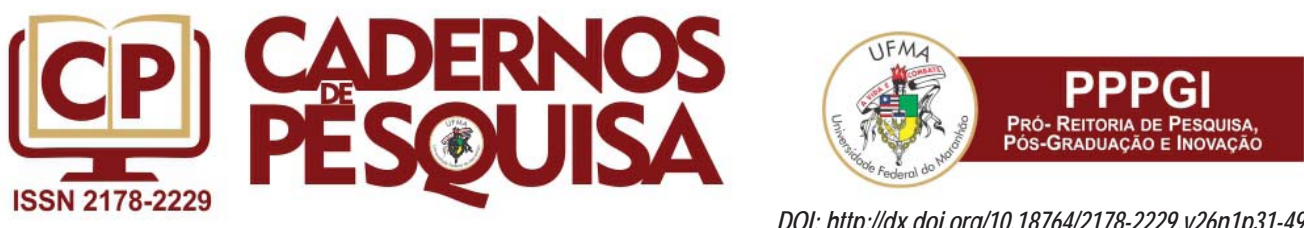

DOI: http://dx.doi.org/10.18764/2178-2229.v26n1p31-49

\title{
A DESIGUALDADE BRASILEIRA REVELADA PELO RESULTADO DE INDICADORES EDUCACIONAIS
}

\section{THE BRAZILIAN INEQUALITY REVEALED BY THE RESULT OF EDUCATIONAL INDICATORS \\ LA DESIGUALDADE BRASILEÑA REVELADA POR EL RESULTADO DE INDICADORES EDUCACIONALES}

\author{
Ricardo Ferreira Vitelli \\ Professor Doutor da Universidade do Vale do Rio dos Sinos. \\ Porto Alegre-RS, Brasil. \\ vitelli@unisinos.br \\ Rosangela Fritsch \\ Professora Doutora da Universidade do Vale do Rio dos Sinos \\ São Leopoldo- RS, Brasil. \\ rosangelaf@unisinos.br \\ Rodrigo Dias da Silva \\ Professor Doutor da Universidade do Vale do Rio dos Sinos. \\ São Leopoldo-RS, Brasil. \\ rodrigods@unisinos.br
}

\section{Resumo}

Este artigo se constitui em um diagnóstico da educação brasileira na década (2004-2014), a partir de informações disponíveis em bancos de dados do Instituto Brasileiro de Geografia e Estatística, levantadas pela Pesquisa Nacional por Amostra de Domicílios, especificamente a partir da análise de dados da área educacional. Apresenta políticase programas educacionais promovidos durante os períodos de gestão presidencial de Lula (2003-2010) e Dilma (2011-2016). A metodologia se baseou em uma pesquisa em fontes secundárias com tratamento estatístico dos dados, bem como suas análises foram desenvolvidas à luz de referenciais teóricos inspirados no Pensamento Social Contemporâneo. Os principais resultados do estudo apontam para um crescimento no acesso à educação para estudantes declarados como pretos ou pardos, assim como na redução das diferenças no acesso à educação entre famílias menos favorecidas economicamente. Contudo, ainda revelama persistência das desigualdades brasileiras, conservando e reproduzindo processos socialmente excludentes para grande parte da população.

Palavras-chave: Educação. Desigualdades Educacionais. Acesso. Permanência.

\begin{abstract}
This article is a diagnosis of Brazilian education in decade (2004-2014), from information available in databases of the Brazilian Institute of Geography and Statistics, raised by the National survey by sample of households, specifically from the data analysis from educational area. Present educational policies and programs promoted during the periods of presidential management Lula (2003-2010) and Dilma (2011-2016). The methodology was based on a research in secondary sources with data statistical treatment, as well as their analyses were developed in light of theoretical references inspired by contemporary social thought. The main results of the study point to a growth in access to education for students declared as black or brown, as well as reducing differences in access to education among economically disadvantaged families. However, they still reveal the persistence of Brazilian inequalities, preserving and reproducing socially excluding processes for a large part of population.
\end{abstract}

Keywords: Education. Educational inequalities. Access. Permanence.

Artigo recebido em dezembro 2017. Aprovado em janeiro de 2019.

Cad. Pesq., v. 26, n. 1, jan./mar., 2019. 


\section{Resumen}

Este artículo se constituye en un diagnóstico de la educación brasileña en la década (2004-2014), a partir de informaciones disponibles en bancos de datos del Instituto Brasileño de Geografía y Estadística, levantadas por la Encuesta Nacional por Muestra de Domicilios, específicamente a partir del análisis de datos del área educativa. Presenta políticas y programas educativos promovidos durante los períodos de gestión presidencial de Lula (2003-2010) y Dilma (2011-2016). La metodología se basó en una investigación en fuentes secundarias con tratamiento estadístico de los datos, así como sus análisis fueron desarrolladas a la luz de referenciales teóricos inspirados en el Pensamiento Social Contemporáneo. Los principales resultados del estudio apuntan a para un crecimiento en el acceso a la educación para estudiantes declarados como negros o pardos, así como en la reducción de las diferencias en el acceso a la educación entre familias menos favorecidas económicamente. Sin embargo, todavía revelan la persistencia de las desigualdades brasileñas, conservando y reproduciendo procesos socialmente excluyentes para gran parte de la población.

Palabras-clave: Educación. Desigualdades Educacionales. Acceso. Permanencia.

\section{INTRODUÇÃO}

A realidade educacional brasileira é marcada por processos de exclusão, onde quem fica de fora do campo escolar são populações com condições sociais e econômicas menos favorecidas. Uma das pautas frequentes de discussão são as políticas de acesso e permanência dos estudantes no sistema de ensino, a partir das quais constata-se que nem todos ainda têm acesso à educação formal, assim como há uma razoável proporção da população escolar que não consegue permanecer nos bancos escolares. A universalização do ensino ainda é um desafio, pois mesmo no ensino fundamental não está concretizada tendo em vista que cerca de 430 mil crianças de 6 a 14 anos permanecem fora da escola. No ensino médio, cerca de $17,4 \%$ dos jovens de 15 a 17 anos não estão estudando ${ }^{1}$. $\mathrm{O}$ acesso à educação formal não garante a permanência no sistema, perceptível pelas elevadas taxas de abandono escolar, principalmente no ensino médio.

Em um quadro social em que as desigualdades escolares e as desigualdades sociais parecem se multiplicar (DUBET, 2003), este artigo tem como objetivo analisar as desigualdades educacionais por meio de um diagnóstico da educação brasileira no período 2004-2014 apontando políticas e programas educacionais que podem ter sido intervenientes nos resultados dos indicadores apresentados.

Para contribuir na compreensão dessa problemática, optamos pela busca de informações a respeito de alguns indicadores, com segmentação de públicos ou períodos, avaliando a evolução desses indicadores ao longo do tempo. A metodologia se baseou em uma pesquisa em fontes secundárias (sites), na qual as análises quantitativas tiveram tratamento estatístico dos dados e as qualitativas foram desenvolvidas à luz de referenciais teóricos inspirados no Pensamento Social Contemporâneo.

O estudo é resultado depesquisa em banco de dados do Instituto Brasileiro de Geografia e Estatística (IBGE)2, utilizando-se de dados da Pesquisa Nacional por Amostra de Domicílios (PNAD)ª , período 2004-2014, cujas informações estatísticas são discutidas de modo a estabelecermos uma relação com as políticas públicas educacionais efetivadas no referido período. No site do Ministério da Educação (MEC), foram mapeadas políticas e programas educacionais promovidos durante os períodos de gestão presidencial de Luiz Inácio Lula da Silva ${ }^{4}(2003-2010)$ e Dilma Rousseff ${ }^{5}$ (2011-2014).

2 Segundo o site o IBGE é uma entidade da administração pública federal, vinculada ao Ministério do Planejamento, Desenvolvimento e Gestão e tem como missão institucional Retratar o Brasil com informações necessárias ao conhecimento de sua realidade e ao exercício da cidadania (INSTITUTO BRASILEIRO DE GEOGRAFIA E ESTATÍSTICA, [199-]).

3 É uma pesquisa por amostra probabilística de domicílios, de abrangência nacional, planejada para atender a diversos propósitos. Visa produzir informações básicas para o estudo do desenvolvimento socioeconômico do País e permitir a investigação contínua de indicadores sobre trabalho e rendimento. Os principais indicadores que serão produzidos com base na PNAD Contínua (INSTITUTO BRASILEIRO DE GEOGRAFIA E ESTATÍSTICA, 2016b).

Passaremos a nomear como Lula.

5 Passaremos a nomear como Dilma.
} 
Avaliamos indicadores educacionais mensurados pela $\mathrm{PNAD}^{6}$ como fonte de referência para um diagnóstico da educação brasileira pelo viés da desigualdade educacional. A busca das informações foi estabelecida em função da confiabilidade dos dados e da amplitude dos mesmos. A PNAD é identificada como fonte de referência oficial de Estado para formulação de políticas públicas, seus dados encontravam-se disponíveis por ano de realização das pesquisas em arquivos específicos. Na busca dos dados houve um processo de sumarização dos mesmos. Com isso, foi possível identificar a evolução histórica dos resultados dos indicadores, no período pesquisado.

O termo indicador se configura etimologicamente como algo que indica, aponta; algo como se fosse um sinal. Os indicadores expressam ou quantificam um resultado, uma característica ou desempenho de uma ação, processo ou serviço. A literatura aponta diversas concepções de indicadores.

O indicador é uma medida, de ordem quantitativa ou qualitativa, dotada de significado particular e utilizada para organizar e captar as informações relevantes dos elementos que compõem o objeto da observação. É um recurso metodológico que informa empiricamente sobre a evolução do aspecto observado. (FERREIRA; CASSIOLATO; GONZALEZ, 2009, p. 24).

Jannuzzi $(2009,2011,2016)$ utiliza uma conceituação de indicador com uma amplitude social. Em seus estudos, um indicador social serve para subsidiar o planejamento público assim como para a formulação de políticas sociais. Concebe, então, um indicador social como sendo uma

\begin{abstract}
Medida em geral quantitativa dotada de significado social substantivo, usado para substituir, quantificar ou operacionalizar um conceito social abstrato, de interesse teórico (para pesquisa acadêmica) ou programático (para formulação de políticas). É um recurso metodológico, empiricamente referido, que informa algo sobre um aspecto da realidade social ou sobre mudanças que estão se processando na mesma. (JANNUZZI, 2011, p. 1).
\end{abstract}

Existe certa confluência na definição de indicadores "como parâmetros quantificados ou qualitativos que servem para detalhar se os objetivos de uma proposta estão sendo bem conduzidos (avaliação de processo) ou foram alcançados (avaliação de resultados)" (MINAYO, 2009, p. 84). Do ponto de vista de políticas públicas, os indicadores são instrumentos que permitem identificar e medir aspectos relacionados a um determinado conceito, fenômeno, problema ou resultado de uma intervenção na realidade. A principal finalidade de um indicador é "traduzir, de forma mensurável, determinado aspecto de uma realidade dada (situação social) ou construída (ação de governo), de maneira a tornar operacional a sua observação e avaliação" (BRASIL, 2010). Para Minayo (2009, p. 84), como uma espécie de sinalizadores da realidade, a maioria dos indicadores dá ênfase ao sentido de medida e balizamento de processos de construção da realidade ou de elaboração de investigações avaliativas.

Januzzi (2016, p. 628) afirma ainda que "a dificuldade na construção de indicadores é maior em situações em que políticas e programas sociais se estruturam de modo sistêmico, envolvendo muitas atividades concomitantes, operados por muitos agentes, em contextos heterogêneos de gestão e oferta de serviços". Frente a isto, propõe uma abordagem sistêmica na avaliação de políticas e programas complexos, um "processo de construção de um sistema de indicadores para intervenções públicas mais complexas" (JANUZZI, 2016).

Além da introdução, opresente artigo se divide em mais três seções: a primeira, explicita os pressupostos teórico-metodológicos do estudo; a segunda, aborda os resultados e discussões; e a última, tece as considerações finais.

\footnotetext{
Segundo o sítio do IBGE (http://ibge.gov.br), a PNAD tem por objetivo obter informações anuais sobre características demográficas e socioeconômicas da população entre outras, tendo como unidade de coleta os domicílios. Temas específicos abrangendo aspectos demográficos, sociais e econômicos tambémsão investigados. Em anos de levantamento de dados para o censo demográfico a PNAD não é realizada (2010).
} 


\section{PRESSUPOSTOS TEÓRICO-METODOLÓGICOS}

A luta por políticas públicas de Estado, para a garantia da educação como direito social e pela qualidade social da Educação no Brasil, se dá em um contexto de globalização neoliberal, com governos fortemente comprometidos com interesses empresariais e a serviço do processo de acumulação do capital (TEODORO, 2011; BALL, 2014).

$\mathrm{Na}$ atual conjuntura, predominam estratégias de reformas e ajuste fiscal para a superação da crise estrutural do capital que revogam o fortalecimento da lógica neoliberal e da globalização econômica. Esse cenário afeta visceralmente a educação, tanto pela internacionalização das políticas educacionais pautadas por agências internacionais, quanto pela configuração de um Estado Mínimo em serviços sociais e com forte caráter avaliador (AKKARI, 2011).

A democratização de um país como o Brasil, com enormes desigualdades sociais, tem sido arduamente perseguida por forças e movimentos progressistas, particularmente a partir da década de 1980, com alguns avanços e muitos retrocessos. A Constituição Federal de 1988 representa um desses avanços, especialmente quando explicita como direitos sociais no art. $6^{\circ}$ : "a educação, a saúde, a alimentação, o trabalho, a moradia, o transporte, o lazer, a segurança, a previdência social, a proteção à maternidade e à infância, a assistência aos desamparados, na forma desta Constituição" (BRASIL, 1988). A Lei de Diretrizes e Bases da Educação (LDBN, 1996), no art. $3^{\circ}$ coloca que o ensino será ministrado com base nos seguintes princípios:

I - igualdade de condições para o acesso e permanência na escola; II - liberdade de aprender, ensinar, pesquisar e divulgar a cultura, o pensamento, a arte e o saber; III - pluralismo de ideias e de concepções pedagógicas; IV - respeito à liberdade e apreço à tolerância; $V$ - coexistência de instituições públicas e privadas de ensino; VI - gratuidade do ensino público em estabelecimentos oficiais; VII - valorização do profissional da educação escolar; VIII - gestão democrática do ensino público, na forma desta Lei e da legislação dos sistemas de ensino; IX - garantia de padrão de qualidade; $X$ - valorização da experiência extraescolar; XI - vinculação entre a educação escolar, o trabalho e as práticas sociais; XII - consideração com a diversidade étnico-racial. (BRASIL, 1996a).

No período de 2004 a 2014, tivemos a realização de duas Conferências Nacionais de Educação (CONAE 2010 e 2014) que mobilizaram a sociedade civil organizada no país e tiveram como pautas centrais a qualidade social da educação e a instituição do Sistema Nacional de Educação, entendido como:

[...] um aperfeiçoamento na organização da educação nacional, sustentada por um pacto federativo construído de forma democrática e inscrito em um conjunto de leis nacionais, capazes de orientar cada sistema ou rede de ensino para que o direito constitucional inalienável seja garantido, com equidade, a cada cidadão brasileiro. (BRASIL, 2015).

Os movimentos culminaram com a aprovação do Plano Nacional de Educação (PNE), Lei $n^{\circ} 13.005 / 2014$, que se colocava como um plano de Estado decenal e estabelecia em seu art. 13 que:

o poder público deverá instituir, em lei específica, contados 2 (dois) anos da publicação desta Lei, o Sistema Nacional de Educação ${ }^{7}$, responsável pela articulação entre os sistemas de ensino, em regime de colaboração, para efetivação das diretrizes, metas e estratégias do Plano Nacional de Educação. (BRASIL, 2014).

De toda forma, as políticas públicassão ainda insuficientes frente a uma realidade educacional excludente que não se caracteriza como direito social universal. Uma educação para poucos, ou para determinados grupos, também se constitui como um

\footnotetext{
7 A proposta de Lei Complementar que institui o Sistema Nacional de Educação ainda está em tramitação no Congresso Federal.
} 
aspecto evidenciado em estudos dessa natureza (DUBET, 2003; SAMPAIO; OLIVEIRA, 2015).

O Brasil, um país com grande dimensão territorial e com diferentes realidades regionais, se constituiu com uma história de desigualdades construída e sedimentada ao longo do tempo. A desigualdade social, quando observada por meio de indicadores de renda, normalmente é mensurada por indicadores quantitativos. Essa caracterização acontece principalmente com o advento da globalização e da necessidade imposta de apresentar comparações entre nações ou grupos sociais. Ainda que esse fato não seja novo, assume maior proporção a partir da ideia de globalização.

[...] o conceito de pobreza é relativo, refletindo os hábitos, valores e costumes de uma sociedade; entretanto, com a globalização, essa noção passa a aproximar-se de uma medida comum. Os indicadores utilizados para estimar o grau de pobreza de uma sociedade partem de medidas quantitativas comparativas, demarcando os estratos sociais que enfrentam os mais baixos padrões de vida. (SPOSATI, 1997, p. 13).

Utilizamos dados de identificação da pobreza como parte da constituição do que seja desigualdade social, pois, conforme Campos (2003), pobreza, desigualdade e exclusão são termos que caracterizam situações diferenciadas, mas que se interrelacionam, e, com o advento da globalização, essas expressões passam a se tornar uma medida comum (SPOSATI, 1997). Diferentes podem ser os coeficientes elaborados com a intencionalidade de mensurar as dimensões das desigualdades, contudo, como observa Dubet (2003), tais indicações podem escamotear processos mais enraizados de exclusão ou de significantes desigualdades. A redução numérica em determinados indicadores, se cotejados de maneira isolada, não significa que a sociedade esteja se tornando igualitária, mas pode-se analisar, com atenção, que algumas desigualdades podem estar em retração enquanto outras podem estar se multiplicando (DUBET, 2003).

A desigualdade de renda traz consigo a desigualdade de acesso à educação, saúde, habitação, segurança, justiça e todos os serviços básicos necessários para o bem-estar dos indivíduos. Essa realidade pode ser alterada a partir de um conjunto de políticas públicas sociais que permitam um acesso mais universal e de qualidade para todos, principalmente aqueles com condições menos favoráveis.

Ainda nesse contexto, a avaliação da qualidade da educação, constituída de forma única, busca avaliar igualmente sujeitos que se constituem por desiguais. A forma coletiva de pensar a padronização da qualidade da educação sem levar em conta as diferenças existentes entre os atores e os espaços envolvidos é preocupante, uma vez que se apresenta como capaz de identificar e comparar a qualidade ofertada entre escolas ou redes. Considerando que os indivíduos são, por natureza, desiguais, até mesmo por terem sido constituídos como desiguais em função de modelos econômicos adotados, a avaliação da qualidade da educação feita pelo Estado, fica pautada no uso de indicadores quantitativos de mensuração da qualidade. Arroyo (2011, p. 84) destaca que:

\footnotetext{
Ainda está arraigada a visão de que ser desiguais em percursos escolares os tornam desiguais nos percursos sociais. Essa redução das desigualdades ao escolar não tem empobrecido a relação que se prometia tão fecunda entre políticas-gestãodesigualdades? O escolar dá conta da complexa produção-reprodução das nossas desigualdades sociais? Que consequências têm para as políticas educacionais pensá-las como corretivas das desigualdades sociais, raciais, de gênero, de território? Esquecer essa complexidade não termina empobrecendo a visão das próprias desigualdades escolares, das políticas e sua gestão e avaliação?
}

Pela visão do autor, quanto mais as avaliações colocam o foco nas condições dos alunos de forma padronizada, não respeitando suas diferenças. Não coloca na escola o papel de reprodutor das desigualdades, "ao condenarmos o aluno e seus coletivos de 
origem inocentamos os sistemas, o Estado e suas instituições. Inocentamos a história de reprodução das desigualdades" (ARROYO, 2011, p. 85).

Com isso, não se deve desconsiderar também o fato de que a desigualdade é reforçada pela escola como mais um agente reprodutor dessa desigualdade. $\mathrm{O}$ autor destaca também que "essas políticas generalistas não conseguem esquecer que os diferentes existem e se armam de mecanismos de avaliação para comprovar se cabem ou não nos ideais de igualdade" (ARROYO, 2011, p. 88).

\section{RESULTADOS E DISCUSSÕES}

Em termos de governo do Estado brasileiro situaremos, brevemente, o governo de Fernando Henrique Cardoso (FHC) (1995-2002), colocando em destaque os governos Lula (2003-2010) e Dilma (2011-2016) por se situarem no recorte temporal analisado. São governos que tiveram os presidentes eleitos por voto, imprimiram de forma mais concreta esforços em reformas educacionais, ainda que tenham assumido objetivos e compromissos diversos, sofreram influências de organismos e agências multilaterais.

O governo FHC, do Partido da Social Democracia Brasileira (PSDB), foi marcado pela estabilidade econômica alcançada por meio do Plano Real. Promoveu importante reforma do Estado brasileiro, no sentido de sua racionalização e modernização com a privatização de empresas, a criação das agências regulatórias e a mudança da legislação que rege o funcionalismo público, bem como a introdução de programas de transferência de renda como o Bolsa Escola. Priorizou o ensino fundamental na política de financiamento, via a instituição do Fundo de Manutenção e Desenvolvimento do Ensino Fundamental e de Valorização do Magistério (FUNDEF). "O conjunto de reformas implantadas na educação brasileira nesse período resultou na reestruturação do ensino no Brasil nos seus aspectos relativos à organização escolar, à redefinição dos currículos, à avaliação, à gestão e ao seu financiamento" (OLIVEIRA, 2009, p. 199). Em 2001, foi criado o Fundo de Financiamento Estudantil (FIES), destinado a financiar a graduação na educação superior de estudantes matriculados em cursos superiores não gratuitos. Destaca-se ainda o aperfeiçoamento do Sistema de Avaliação da Educação Básica (SAEB), que passou a contemplar novas modalidades de exames, abrangendo da educação básica à superior que se concentraram na avaliação dos egressos, como o caso do Exame Nacional de Cursos - O Provão - e o Exame Nacional do Ensino Médio (ENEM).

Lula, do Partido dos trabalhadores (PT), ascende ao poder com a perspectiva de priorizar a Educação através do programa "Uma escola do tamanho do Brasil", pautado pela democratização do acesso e pela garantia da permanência e da qualidade social da educação, sob a instauração de um Regime de Colaboração e democratização da gestão. "Em 2003, o presidente Lula da Silva assumiu o governo do País com o objetivo central de promover o desenvolvimento com justiça social" (SCAF; FONSECA, 2016).

O público alvo foi constituído pelas classes sociais mais desfavorecidas destacandose neste sentido o programa Bolsa-Família (BRASIL, 2004) que teve a finalidade de transferência direta de renda do governo para famílias pobres e em extrema miséria. O programa de 2006 amplia a política de financiamento em relação ao FUNDEF com a criação do Fundo de Manutenção e Desenvolvimento da Educação Básica e Valorização dos Profissionais da Educação (FUNDEB) compreendendo agora suas três etapas: Educação Infantil, Ensino Fundamental e Ensino Médio (BRASIL, 2007).

No segundo mandato, no planejamento para 2007, foi instituído o Programa de Aceleração do Crescimento (PAC) e o Plano de Desenvolvimento da Educação (PDE) com a intencionalidade do PDE se legitimar como um Plano de Estado para a Educação, tendo como prioridade a melhoria da qualidade da educação básica.

Ainda em 2007, foi lançado o Plano de Metas Compromisso Todos pela Educação explicitando a luta pelo direito de um ensino público de qualidade em regime de colaboração, pauta das reformas educacionais desde a década de 1980, associada 
a uma política que se integra ao PDE. O Plano se colocou como a conjugação dos esforços da União, dos Estados, do Distrito Federal e dos Municípios, atuando em regime de colaboração com as famílias e a comunidade, em proveito da melhoria da qualidade da educação básica. O apoio da União aos entes federados ocorreu mediante a elaboração de um Plano de Ações Articuladas (PAR), orientado a partir dos seguintes eixos: gestão educacional, formação de professores e profissionais de serviços e apoio escolar, recursos pedagógicos e infraestrutura física.

Em 2009, a Ementa Constituição $n^{\circ} 59$, reforça o sentido da ampliação do direito à educação ampliando a obrigatoriedade do ensino gratuito para a educação básica, dos 4 aos 17 anos de idade (antes era apenas no nível fundamental) indicando, além disso, a necessidade de assegurar o acesso, a permanência e a conclusão para todos. Também, institui a colaboração entre os sistemas de ensino, estabelece duração decenal para o PNE que deveria e estabeleceu a meta de aplicação de recursos públicos em educação em proporção ao Produto Interno Bruto (PIB) (BRASIL, 2009). No quadro 1, destacamos os principais programas no âmbito educacional dos Governo Lula que abrangem o período de recorte temporal desse artigo.

Quadro 1 - Principais programas e ações educacionais do Governo Lula (2003-2010).

\begin{tabular}{|c|c|c|c|}
\hline Ano & Programas & Amparo legal & Escopo \\
\hline 2003 & Rede Nacional de Formação Continuada. & $\begin{array}{l}\text { Edital Seif/MEC port. } n^{0} 1403 \text {, de } 9 \text { de } \\
\text { junho de } 2003 .\end{array}$ & $\begin{array}{l}\text { Melhoria da formação dos professores e alunos, tendo } \\
\text { como público-alvo prioritário professores de educação } \\
\text { básica dos sistemas públicos de educação. }\end{array}$ \\
\hline 2004 & $\begin{array}{l}\text { Programa Universidade para Todos } \\
\text { (ProUni). }\end{array}$ & $\begin{array}{l}\text { Medida Provisória } n^{0} 213 \text {, de } 10 \text { de } \\
\text { setembro de } 2004 \text {, Lei } n^{0} 11.096 \text {, de } 13 \\
\text { de janeiro de } 2005 \text { e Lei } n^{0} 11.128 \text {, de } \\
28 \text { de junho de } 2005 \text { alterada pela Lei } n^{0} \\
11.482 \text {, de } 31 \text { de maio de } 2007 \text {. }\end{array}$ & $\begin{array}{l}\text { Concessão de bolsas de estudo integrais e parciais } \\
\text { em cursos de graduação e sequenciais de formação } \\
\text { específica, em instituições privadas de educação superior. }\end{array}$ \\
\hline 2005 & $\begin{array}{l}\text { Programa Nacional Escola de gestores } \\
\text { da Educação Básica Pública. }\end{array}$ & $\begin{array}{l}\text { Portaria } n^{0} 145 \text {, de } 11 \text { de fevereiro de } \\
2009 .\end{array}$ & Formação continuada de gestores escolares. \\
\hline 2006 & Universidade Aberta do Brasil (UAB). & $\begin{array}{l}\text { Decreto } n^{0} 5.800 \text {, de } 8 \text { de junho de } \\
2006 .\end{array}$ & $\begin{array}{l}\text { Sistema integrado por universidades públicas que oferece } \\
\text { cursos de nível superior para camadas da população que } \\
\text { têm dificuldade de acesso à formação universitária, por } \\
\text { meio do uso da metodologia da educação a distância. }\end{array}$ \\
\hline 2006 & Observatório da Educação. & $\begin{array}{l}\text { Decreto Presidencial } n^{0} 5.803 \text {, de } 08 \text { de } \\
\text { junho de } 2006 .\end{array}$ & $\begin{array}{l}\text { Crescimento da produção acadêmica e a formação de } \\
\text { recursos humanos pós-graduação, nos níveis de mestrado } \\
\text { e doutorado, por meio de financiamento específico. }\end{array}$ \\
\hline 2007 & $\begin{array}{l}\text { Índice de Desenvolvimento da Educação } \\
\text { Básica (IDEB). }\end{array}$ & $\begin{array}{l}\text { Decreto } n^{0} 6.094 \text {, de } 24 \text { de abril de } \\
2007 .\end{array}$ & $\begin{array}{l}\text { Indicador para medir a qualidade da educação que } \\
\text { combina os dados de fluxo escolar, especificamente, } \\
\text { as taxas de aprovação - obtidas a partir do Censo da } \\
\text { Educação Básica - com os dados de desempenho escolar } \\
\text { - fornecidos pela Prova Brasil e pelo Sistema de Avaliação } \\
\text { da Educação Básica (SAEB). }\end{array}$ \\
\hline 2007 & Programa Mais Educação. & $\begin{array}{l}\text { Portaria Normativa Interministerial } n^{0} \\
17 \text {, de } 24 \text { de abril de } 2007 \text { e o Decreto } \\
n^{0} 7.083 \text {, de } 27 \text { de janeiro de } 2010 \text {. }\end{array}$ & $\begin{array}{l}\text { Melhoria da aprendizagem, por meio da ampliação do } \\
\text { tempo de permanência de crianças, adolescentes e jovens } \\
\text { matriculados em escola básica, oferecendo ensino em } \\
\text { tempo integral. }\end{array}$ \\
\hline 2007 & $\begin{array}{l}\text { Programa Nacional de Reestruturação e } \\
\text { Aparelhagem da Rede Escolar Pública de } \\
\text { Educação Infantil (Prolnfância). }\end{array}$ & $\begin{array}{l}\text { Resolução CD/FNDE n } 6 \text {, de } 24 \text { de } \\
\text { abril de } 2007 .\end{array}$ & $\begin{array}{l}\text { Assistência financeira, em caráter suplementar, ao Distrito } \\
\text { Federal e aos municípios que efetuaram o Termo de } \\
\text { Adesão ao Plano de Metas Compromisso Todos pela } \\
\text { Educação e elaboraram o PAR. }\end{array}$ \\
\hline 2007 & $\begin{array}{l}\text { Programa de Apoio a Planos de } \\
\text { Reestruturação e Expansão das } \\
\text { Universidades Federais (REUNI). }\end{array}$ & $\begin{array}{l}\text { Decreto } n^{0} 6.096 \text {, de } 24 \text { de abril de } \\
2007 .\end{array}$ & $\begin{array}{l}\text { Ampliação do acesso e a permanência na educação } \\
\text { superior, no nível de graduação, pelo melhor } \\
\text { aproveitamento da estrutura física e de recursos humanos } \\
\text { existentes nas universidades federais. }\end{array}$ \\
\hline 2008 & Piso salarial nacional. & Lei $n^{0} 11.738$, de 16 de julho de 2008. & $\begin{array}{l}\text { Regulamentação do piso salarial profissional nacional para } \\
\text { os profissionais do magistério público da educação básica. }\end{array}$ \\
\hline 2008 & $\begin{array}{l}\text { Reestruturação e expansão Rede } \\
\text { Federal de Educação Profissional, } \\
\text { Científica e Tecnológica e criação dos } \\
\text { Institutos Federais de Educação, Ciência } \\
\text { e Tecnologia. }\end{array}$ & $\begin{array}{l}\text { Lei } n^{0} 11.892 \text {, de } 29 \text { de dezembro de } \\
2008 .\end{array}$ & $\begin{array}{l}\text { Ampliação da oferta de vagas da educação profissional e } \\
\text { tecnológica mediante implantação de novas unidades de } \\
\text { ensino, vinculadas aos Institutos Federais de Educação, } \\
\text { Ciência e Tecnologia. }\end{array}$ \\
\hline 2009 & $\begin{array}{l}\text { Plano Nacional de Formação dos } \\
\text { Professores da Educação Básica } \\
\text { (PARFOR). }\end{array}$ & $\begin{array}{l}\text { Decreto } n^{0} 6.755 \text {, de } 20 \text { de janeiro de } \\
2009 \text {, Portaria } n^{0} 9 \text {, de } 30 \text { de junho de } \\
2009 .\end{array}$ & $\begin{array}{l}\text { Formação de professores, oferta de educação superior, } \\
\text { gratuita e de qualidade, para professores em exercício na } \\
\text { rede pública de educação básica. }\end{array}$ \\
\hline 2009 & Programa Caminho da Escola. & $\begin{array}{l}\text { Decreto } n^{0} 6.768 \text {, de } 10 \text { de fevereiro de } \\
2009 \text {, Resolução } n^{0} 7 \text {, de } 23 \text { de abril de } \\
2010 .\end{array}$ & Renovação da frota de veículos escolares. \\
\hline
\end{tabular}




\begin{tabular}{|c|l|l|l|}
\hline Ano & \multicolumn{1}{|c|}{ Programas } & \multicolumn{1}{|c|}{ Amparo legal } & \multicolumn{1}{|c|}{ Escopo } \\
\hline 2009 & Programa Ensino Médio Inovador (EMI). & $\begin{array}{l}\text { Portaria } n^{0} \text { 971, de 9 de outubro de } \\
2009 .\end{array}$ & $\begin{array}{l}\text { Fortalecimento dos Sistemas de Ensino Estaduais e } \\
\text { Distrital no desenvolvimento de propostas curriculares } \\
\text { inovadoras nas escolas de Ensino Médio. }\end{array}$ \\
\hline 2010 & $\begin{array}{l}\text { Programa Institucional de Bolsa de } \\
\text { Iniciação à Docência (PIBID). }\end{array}$ & $\begin{array}{l}\text { Decreto no 7.219, de 24 de julho de } \\
2010 .\end{array}$ & $\begin{array}{l}\text { Formação de professores, apoio estudantes de licenciatura } \\
\text { plena das instituições públicas e comunitárias, sem fins } \\
\text { econômicos, de educação superior. }\end{array}$ \\
\hline
\end{tabular}

Fonte: Elaborado pelos autores.

Dilma Rousseff, do Partido dos Trabalhadores (2011-2016), governa como primeira mulher eleita dando continuidade ao PDE e aos programas já em andamento com a diretriz de garantir educação para igualdade social, a cidadania e o desenvolvimento. Destacamos em 2012, a Lei de cotas (Lei $n^{\circ} 12.711 / 2012$ ), sancionada em agosto deste ano, que garante a reserva de $50 \%$ das matrículas por curso e turno nas 59 universidades federais e 38 institutos federais de educação, ciência e tecnologia a alunos oriundos integralmente do ensino médio público, em cursos regulares ou da educação de jovens e adultos. Os demais $50 \%$ das vagas permanecem para ampla concorrência (BRASIL, 2012). No quadro 2, apresentamos os principais programas no âmbito educacional dos Governo Dilma que abrangem o período de recorte temporal desse artigo.

Quadro 2 - Principais programas e ações educacionais do Governo Dilma (2011- 2016).

\begin{tabular}{|c|c|c|c|}
\hline Ano & Programas & Amparo legal & Escopo \\
\hline 2011 & $\begin{array}{l}\text { Programa Nacional de Acesso } \\
\text { ao Ensino Técnico e Emprego } \\
\text { (PRONATEC). }\end{array}$ & Lei $n^{\circ} 12.513$, de 26 de outubro de 2011. & $\begin{array}{l}\text { Ampliação da oferta de cursos de educação profissional e } \\
\text { tecnológica por intermédio de programas, projetos e ações } \\
\text { de assistência técnica financeira. }\end{array}$ \\
\hline 2012 & $\begin{array}{l}\text { Pacto Nacional pela Alfabetização na } \\
\text { Idade Certa (PNAIC). }\end{array}$ & $\begin{array}{l}\text { Portaria } n^{0} 1.458 \text {, de } 14 \text { de dezembro } \\
\text { de 2012, Lei } n^{0} 12.801 \text {, de } 24 \text { de abril } \\
\text { de } 2013 \text {. }\end{array}$ & $\begin{array}{l}\text { Apoio técnico e financeiro da União aos entes federados } \\
\text { no âmbito do Pacto Nacional pela Alfabetização na Idade } \\
\text { Certa. }\end{array}$ \\
\hline 2013 & $\begin{array}{l}\text { Pacto Nacional pelo Fortalecimento } \\
\text { do Ensino Médio. }\end{array}$ & $\begin{array}{l}\text { Portaria Ministerial No } 1.140 \text {, de } 22 \text { de } \\
\text { novembro de } 2013 .\end{array}$ & $\begin{array}{l}\text { Valorização da formação continuada dos professores e } \\
\text { coordenadores pedagógicos que atual no ensino médio } \\
\text { público. }\end{array}$ \\
\hline 2014 & Ciência sem Fronteira. & $\begin{array}{l}\text { Portaria no - } 973 \text {, de } 14 \text { de novembro } \\
\text { de } 2014 \text {. }\end{array}$ & $\begin{array}{l}\text { Consolidação, expansão e internacionalização da ciência } \\
\text { e tecnologia, da inovação e da competitividade brasileira } \\
\text { por meio do intercâmbio e da mobilidade internacional. }\end{array}$ \\
\hline
\end{tabular}

Fonte: Elaborado pelos autores.

Pelos quadrosanteriores, que não esgotam todos os programas instituídos no período demarcado, pode-se verificar que os mesmos abrangeram todas as etapas do sistema educacional brasileiro: educação básica (educação infantil, ensino fundamental e ensino médio), educação superior e educação técnica e profissional. Além disto, percebe-se a intencionalidade de avançar na melhoria da qualidade da educação brasileira pelo número expressivo de programas e pela abrangência de escopos, com estratégias que impactam nos currículos, na avaliação, na formação docente e de gestores, na pesquisa, no financiamento, na infraestrutura e em serviços de apoio.

O primeiro indicador avaliado foi a taxa de escolarização bruta. A taxa de escolarização bruta permite que se compare o total da matrícula em um dado nível de ensino com a população na faixa etária adequada a esse nível. É importante considerar nesse indicador a relevância dos seguintes aspectos: na quantidade de matrícula incluem-se também estudantes que não estão na faixa etária indicada (alunos retidos) e a faixa etária indicada pode conter estudantes em outros níveis de ensino (inclusive superiores ao indicado).

O resultado deste indicador representa o acesso ao sistema educacional, bem como a permanência dos estudantes no sistema. Ainda que haja, de modo geral, um crescimento no resultado do indicador, a taxa da educação superior ainda tem o menor valor, indicando a formação nesse nível como sendo para poucos e, ao mesmo tempo, é uma taxa que muito pouco se alterou no período de 10 anos pesquisado. Ao mesmo tempo, se observa que a taxa da educação fundamental é maior que a do ensino médio, que é maior que a da educação superior. Três pontos importantes representam esses comportamentos: a evasão, caracterizada pelos estudantes que não seguem no sistema (problema de permanência); mesmo aqueles que gostariam de permanecer no 
sistema são impedidos pela limitação de vagas disponíveis; repetidas reprovações não permitem que os estudantes deem vasão ao fluxo escolar, retendo os mesmos.

A universalização da Educação Básica em que o tempo de duração da escolaridade obrigatória e gratuita se amplia, assegurada inclusive sua oferta gratuita para todos os que a ela não tiveram acesso na idade própria se coloca com a promulgação da Ementa Constitucional $n^{\circ} 59$, sendo uma política educacional recente no Brasil. A partir dela os brasileiros passarão a ter direito a catorze anos de ensino gratuito. Até então era assegurado o ensino fundamental, obrigatório e gratuito. Não existe nenhum amparo legal em relação a Educação Superior.

Um aspecto relevante a considerar diz respeito a outro indicador educacional, o dedefasagem idade-série, ou seja, estudantes com idade acima de dois anos da idade adequada ao nível escolar é oriundo de problemas de fluxo escolar. Segundo um estudo realizado por Fritsch, Vitelli e Rocha (2014) a defasagem é um indicador que também interfere no andamento do fluxo escolar, uma vez que o estudante estando nessa condição tem $140 \%$ de chance a mais de ser reprovado do que os demais, assim como abandonam mais a escola também. A defasagem é constituída de três formas diferentes: quando o estudante tem seguidas reprovações; quando ingressa tardiamente na escola ou quando necessita parar de estudar por um período de tempo. O ingresso tardio, atualmente, tem menos peso pela obrigatoriedade de matricula na escola. Com isso, a defasagem alimenta as taxas de insucesso escolar.

Quando se considera a quantidade de matrículas incluem-se os estudantes em defasagem. Com isso, a divisão do número de matriculados pela quantidade de estudantes na faixa etária das vagas preenchidas tem que considerar que existem estudantes em defasagem no numeradore que não pertencem a população na idade indicada.

Por outro lado, dois pontos mostram tendência de queda: entre as pessoas com 25 anos ou mais e no total da população brasileira. Algumas considerações podem ser inferidas a respeito desses resultados: mais pessoas atingiram a escolaridade destinada a essa faixa de idade, diminuindo assim a taxa e acontece um movimento de mudança na taxa diminuindo dos pais e aumentando dos filhos, o que poderia ser uma escolha pelo investimento na educação dos filhos.

A redução, ainda que pouco expressiva, na taxa geral do Brasil se explica, quase que preponderantemente, pela redução na taxa de 25 anos ou mais, pois as demais taxas apresentam um aumento ou uma estabilidade. Analisando esse indicadorcomo resultado de políticas de acesso, nesse período pesquisado, mostraum aumento na ocupação dos espaços escolares.

Considerando a taxa de escolarização bruta percentual, no Brasil, é possível identificar a tendência de queda no resultado desse indicador ao longo desse período. Essa queda acontece pela piora nos resultados das pessoas acima de 18 anos de idade.

Nas tabelas a seguir são disponibilizados os dados quantitativos de acordo com que foram divulgados pelo IBGE em Pesquisa Nacional por Amostra de Domicílios (PNAD) entre os períodos de 2004 a 2014. Outros dados que poderiam ajudar no entendimento desses resultados e de seus cruzamentos não estavam disponíveis para a análise evolutiva dos dados. A informação do ano 2010 não surge em função de que é um ano de recenseamento e, portanto, não é realizada a PNAD. A opção pela PNAD ao invés do Censo Populacional é a sua possibilidade de observar o resultado dos indicadores por ano e segmentados, o que no censo ocorre de 10 em 10 anos.

Na tabela 1, é apresentada a taxa de escolarização líquida, que representa o percentual da população em determinada faixa etária que se encontra matriculada no nível de ensino adequado à sua idade. Assim como o indicador anterior, também é necessário atentar para alguns aspectos ao analisar seu resultado: os matriculados 
na faixa etária podem estar em outro nível de escolarização (anterior ou posterior) e a quantidade de pessoas na faixa etária inclui também aqueles que já concluíram seus estudos referentes ao seu nível de ensino indicado.

Tabela 1 - Taxa de escolarizaçãolíquida percentual a estabelecimentos de ensino médio e superior no Brasil, por cor e raça 2007-2014.

\begin{tabular}{c|c|c|c|c}
\hline \multirow{2}{*}{ Anos $^{1}$} & \multicolumn{2}{|c|}{ Brancos } & \multicolumn{2}{c}{ Pretos ou Pardos } \\
\cline { 2 - 5 } & 15 a 17 & 18 a 24 & 15 a 17 & 18 a 24 \\
\hline 2007 & 60,5 & 20,6 & 39,9 & 6,9 \\
2008 & 62,9 & 21,3 & 42,6 & 7,7 \\
2009 & 62,2 & 22,4 & 44,0 & 8,4 \\
2011 & 62,7 & 22,3 & 46,6 & 9,3 \\
2012 & 65,6 & 23,5 & 48,7 & 9,8 \\
2013 & 66,9 & 24,8 & 50,5 & 11,0 \\
2014 & 68,3 & 26,4 & 52,1 & 12,0 \\
\hline
\end{tabular}

Fonte: Instituto Brasileiro de Geografia e Estatística (2016a).

Esse indicador, a partir dessa segmentação, mostra a disparidade existente na educação brasileira com relação a cor e raça. O enfoque desse indicador foi mais destacado nos níveis de ensino médio e superior, onde essa disparidade se acentua. Alguns pontos são importantes de serem destacados. O primeiro diz respeito ao fato de que todos eles, mesmo segmentados apresentaram melhora nos resultados. A melhoria se acentua entre o grupo de pretos ou pardos, saindo de $39,9 \%$ (2007) para $52,1 \%$ (2014), no ensino médio, representando um acréscimo de 12,2 pontos percentuais (pp). Com relação ao ensino superior aumenta de 6,9\% (2007) para 12,0\% (2014), incremento de 5,1 pp.

Apesar da inexistência de política de universalização da Educação Superior, para entender um pouco esses números destacamos programas propulsores de inclusão na Educação Superior: a política de cotas, ou política de ação afirmativa, que reserva vagas de Instituições de Ensino Superior (IES) para alunos de grupos desprivilegiados (seja por critério de raça ou social), assim como o REUNI e criação dos Institutos Federais no âmbito das IES públicas. No âmbito das IES privadas destacamos o ProUni e o FIES.

Outro ponto revelado pelos números é com relação ao fato de que as proporções em qualquer nível de ensino são sempre desfavoráveis na comparação entre os dois segmentos, de brancos e pretos e pardos. Contudo comparando a diferença entre as taxas do ensino médio entre brancos e pardos era de 20,6 pp (2007) em favor dos brancos e passou a ser de 16,2 pp (2014). Com isso, houve uma redução na disparidade. Na educação superior a diferença pró-brancos era de 13,7 pp (2007) e passou a ser de 14,4 pp (2014), esse dado aponta para um pequeno aumento na disparidade. Assim, o incremento do acesso de pretos e pardos não foi suficiente para acompanhar o crescimento geral das matrículas no ensino superior. Esses dados reforçam o fato de não termos ainda uma educação para todos, principalmente na educação superior.

Os dados foram segmentados para análise entre diferentes grupos e apontam para um conjunto importante de informações para melhor entender a fotografia da educação brasileira nesse período. No que diz respeito às regiões do Brasil. De modo geral todas elas crescem no resultado do indicador que mede a taxa de escolarização líquida percentual. Entendendo assim que o crescimento é universalizado. Contudo, quando o resultado da taxa de escolarização líquida é segmentado por região ainda permanecem disparidades nos resultados, ainda que reduzidas. A região mais pobre (norte) tem pior resultado do que a região mais rica (sudeste) no que concerne a este indicador.

Outra segmentação utilizada foi com relação aos quintos de rendimento mensal familiar per capita. Esse indicador é uma medida estatística do grupo das separatrizes. O total da população é separado em cinco partes de igual tamanho (20\%). Assim sendo o primeiro quinto representa os $20 \%$ com menor renda per capita, assim como o quinto grupo os $20 \%$ com maior renda per capita. 
Separatrizes

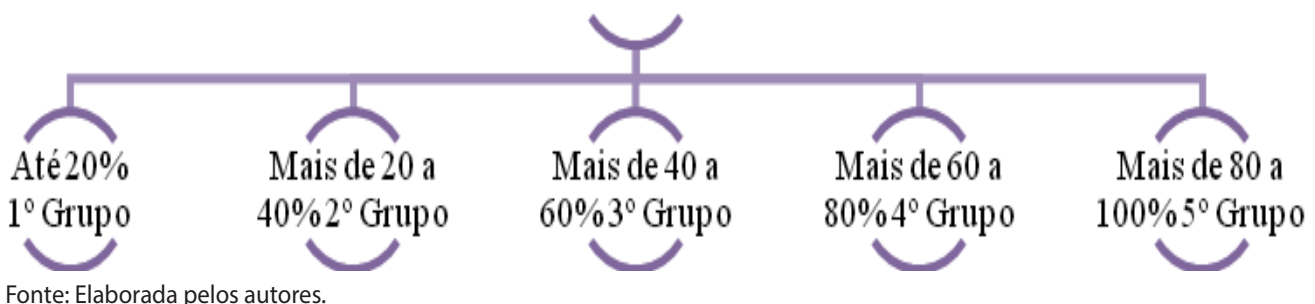

Esse indicador representa uma aproximada relação com a divisão por classes sociais. Ainda que todos os quintos apresentem aumento no resultado dessa taxa, ainda há uma disparidade entre os menores quintos com relação aos maiores quintos. $A$ diferença ente o $5^{\circ}$ e o $1^{\circ}$ passou de 29,8 pp (2007) para 16,5 pp (2014), que representa uma redução significativa.

A tabela 2, apresenta a proporção de crianças de 4 a 5 anos que frequentam estabelecimentos de ensino no Brasil,por regiões e algumas características referentes ao período $2006-2014^{8}$.

\begin{tabular}{|c|c|c|c|c|c|c|c|c|}
\hline \multirow{2}{*}{ Regiões e algumas características selecionadas } & \multicolumn{8}{|c|}{ Proporção de pessoas que frequentam estabelecimento de ensino (\%) } \\
\hline & 2014 & 2013 & 2012 & 2011 & 2009 & 2008 & 2007 & 2006 \\
\hline Brasil & 82,7 & 81,4 & 78,1 & 77,4 & 74,8 & 72,7 & 70,0 & 67,5 \\
\hline Norte & 70,0 & 67,9 & 62,9 & 65,4 & 65,4 & 63,4 & 58,8 & 53,9 \\
\hline Nordeste & 87,7 & 87,0 & 83,9 & 83,4 & 81,4 & 79,3 & 76,8 & 73,7 \\
\hline Sudeste & 85,9 & 85,0 & 82,0 & 81,6 & 79,5 & 76,7 & 75,2 & 73,5 \\
\hline Sul & 78,4 & 73,9 & 70,9 & 66,9 & 59,6 & 59,5 & 56,9 & 53,7 \\
\hline Centro-Oeste & 73,4 & 72,1 & 70,5 & 66,2 & 64,4 & 61,9 & 54,9 & 54,7 \\
\hline Sexo & & & & & & & & \\
\hline Homem & 81,9 & 80,7 & 77,9 & 76,6 & 74,4 & 73,2 & 69,4 & 67,0 \\
\hline \multirow[t]{2}{*}{ Mulher } & 83,5 & 82,0 & 78,4 & 78,3 & 75,1 & 72,2 & 70,7 & 68,0 \\
\hline & & & & & & & & \\
\hline Branca & 85,7 & 83,9 & 79,9 & 79,6 & 76,4 & 75,1 & 72,5 & 70,2 \\
\hline $\begin{array}{l}\text { Preta ou parda } \\
\text { Quintos de rendimento mensal } \\
\text { Familiar per capita nacional }\end{array}$ & 80,4 & 79,4 & 76,9 & 75,7 & 73,5 & 70,7 & 68,0 & 65,3 \\
\hline $1^{\circ}$ quinto & 77,6 & 75,4 & 71,1 & 69,8 & 67,3 & 64,0 & 61,3 & 57,7 \\
\hline $2^{\circ}$ quinto & 81,0 & 79,5 & 75,4 & 75,0 & 73,3 & 69,6 & 67,4 & 64,3 \\
\hline $3^{\circ}$ quinto & 85,8 & 83,7 & 82,2 & 80,2 & 76,7 & 76,3 & 72,5 & 72,9 \\
\hline $4^{\circ}$ quinto & 87,6 & 88,8 & 85,5 & 87,2 & 83,5 & 84,1 & 80,8 & 79,4 \\
\hline $5^{\circ}$ quinto & 94,1 & 93,1 & 92,5 & 91,9 & 91,2 & 91,1 & 89,1 & 87,5 \\
\hline
\end{tabular}

Fonte: Instituto Brasileiro de Geografia e Estatística (2016a).

O indicador evidencia disparidades em relação a cor e raça e entre classes menos favorecidas economicamente na Educação Básica, especificamente na Educação Infantil. Nesta tabela também é possível identificar as desigualdades presentes na educação da faixa de idade de 4 a 5 anos. A região norte é a que apresenta menor presença da faixa etária pesquisada $(70 \%)$ em 2014 , assim como estudantes com famílias no primeiro quinto de renda $(77,6 \%)$, comparado com os demais.

A tabela 3 apresenta os resultados do indicador que mensura a taxa de conclusão do ensino fundamental, segundo as características selecionadas no período especificado.

8 Não havia dados anteriores a 2006. 
Tabela 3 - Taxa de conclusão do ensino fundamental, segundo as Regiões e algumas características selecionadas 2004 a 2014.

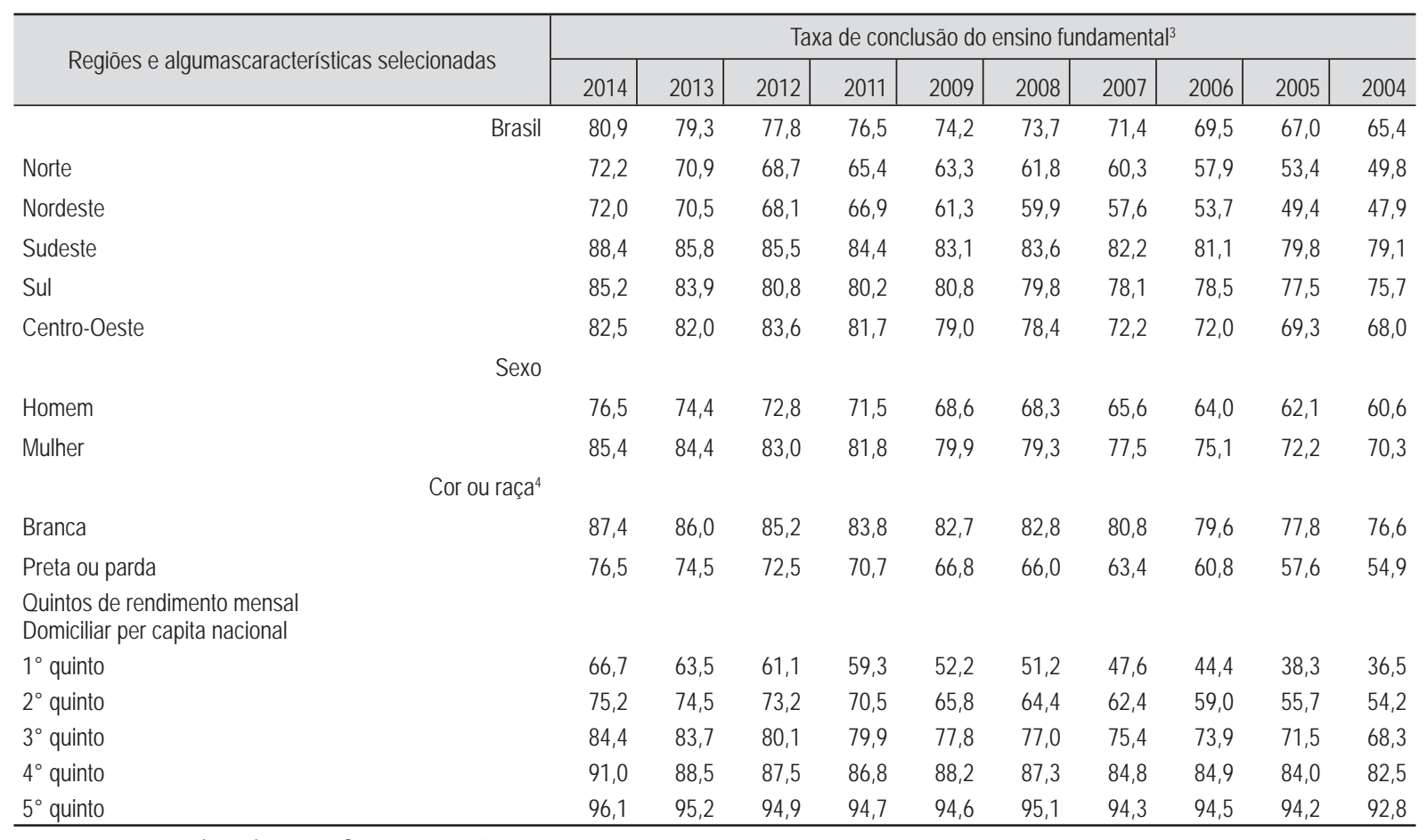

Fonte: Instituto Brasileiro de Geografia e Estatística (2016a).

A taxa de conclusão do ensino fundamental (tabela 3) é um indicador de fluxo escolar, indicando também a permanência do estudante no nível de ensino avaliado. A base de dados se foca, nessa tabela, no ensino fundamental. Assim como o indicador anterior, os dados foram segmentados a partir de algumas características. De modo geral o comportamento desse indicador se assemelha com o anterior, apresenta crescimento no período pesquisado, em qualquer segmentação. As regiões, a situação domiciliar, a raça e o rendimento apresentam diferenças entre os resultados, sendo as regiões mais pobres, em áreas rurais, entre pretos e pardos e em famílias com menores rendimentos os resultados as que apresentam piores resultados.

No que se refere ao ensino fundamental as disparidades apresentadas entre os grupos é ainda maior do que as observadas no indicador anterior, em determinados casos. Nas categorias referentes a situação de domicílio e rendimento as diferenças encontradas para esse nível de ensino são ainda maiores.

Ao analisar o próximo nível de ensino (médio), com base no mesmo indicador, comportamentos semelhantes também são observados. A tabela 4 apresenta os resultados dos indicadores mensurados e segmentados nas mesmas características dos indicadores anteriores. Contudo revela o percentual de estudantes que conseguem concluir o ensino médio.

Tabela 4 - Taxa de conclusão do ensino médio, segundo as Regiões e algumas características selecionadas 2004-2014.

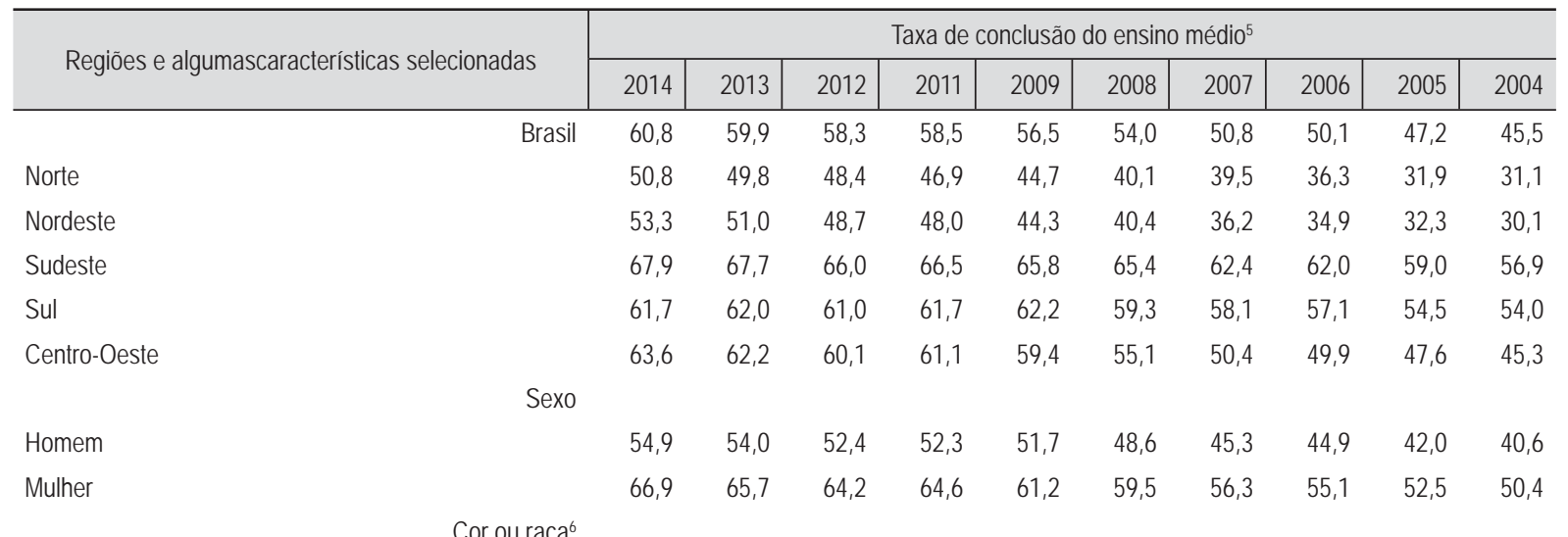




\begin{tabular}{l|r|r|r|r|r|r|r|r|r|r}
\hline \multirow{2}{*}{ Regiões e algumascaracterísticas selecionadas } & \multicolumn{7}{c}{ Taxa de conclusão do ensino médio } \\
\cline { 2 - 10 } & 2014 & 2013 & 2012 & 2011 & 2009 & 2008 & 2007 & 2006 & 2005 & 2004 \\
\hline Branca & 71,7 & 70,4 & 69,4 & 69,3 & 67,4 & 65,4 & 62,8 & 62,6 & 59,4 & 57,9 \\
Preta ou parda & 52,6 & 51,6 & 49,1 & 49,1 & 46,8 & 43,6 & 40,2 & 38,4 & 36,0 & 33,4 \\
Quintos de rendimento mensal & & & & & & & & & & \\
Domiciliar per capita nacional & & & & & & & & & \\
$1^{\circ}$ quinto & 32,9 & 33,1 & 28,7 & 28,9 & 23,7 & 20,1 & 17,6 & 16,9 & 14,7 & 13,7 \\
$2^{\circ}$ quinto & 47,7 & 46,7 & 42,1 & 41,3 & 40,6 & 34,2 & 31,7 & 30,1 & 26,9 & 25,0 \\
$3^{\circ}$ quinto & 61,6 & 60,4 & 59,0 & 57,5 & 53,5 & 52,3 & 48,7 & 47,7 & 42,9 & 39,4 \\
$4^{\circ}$ quinto & 73,1 & 72,2 & 71,2 & 71,3 & 71,3 & 69,6 & 65,2 & 65,1 & 62,3 & 59,1 \\
$5^{\circ}$ quinto & 87,8 & 86,1 & 85,7 & 86,9 & 86,5 & 86,8 & 85,9 & 87,2 & 83,7 & 83,4 \\
\hline
\end{tabular}

Fonte: Instituto Brasileiro de Geografia e Estatística (2016a).

De modo geral houve no período um crescimento no resultado do indicador. Contudo, esses indicadores são inferiores aos apresentados no nível de ensino anterior (fundamental). Começa a se reforçar a problemática de acesso em função da evasão escolar. Nesse nível de ensino as taxas de abandono e reprovação aumentam em comparação com o fundamental. Desta forma, interferem no fluxo escolar e na capacidade desta etapa de ensino de permitir a conclusão dos estudantes.

As maiores diferenças encontradas, em 2014, são entre estudantes brancos e pretos com 19,1 pp e que em 2004 era de 24,5 pp, em favor dos brancos. Além disso, nas famílias mais ricas em comparação com as mais pobres, em 2014, a diferença é de 54,9 pp, contra 69,7 pp. Em ambos os casos houve uma redução na disparidade dos resultados, ainda assim a diferença no resultado dos indicadores ainda é preocupante.

A apresentação do indicador da tabela 5 , que representa o percentual de estudantes de 18 a 24 anos, segmentado por raça e nível de ensino. Cabe ressaltar que os resultados não incluem os estudantes em cursos pré-vestibulares, supletivos ou em alfabetização de adultos.

\begin{tabular}{|c|c|c|c|c|c|c|}
\hline \multirow{2}{*}{ Anos } & \multicolumn{3}{|c|}{ Brancos } & \multicolumn{3}{|c|}{ Pretos ou Pardos } \\
\hline & Fundamental & Médio & Superior $^{7}$ & Fundamental & Médio & Superior \\
\hline 2004 & 8,7 & 31,4 & 47,2 & 23,6 & 47,3 & 16,7 \\
\hline 2005 & 7,5 & 29,6 & 51,5 & 22,2 & 45,7 & 18,9 \\
\hline 2006 & 7,0 & 26,1 & 55,9 & 19,3 & 45,8 & 21,9 \\
\hline 2007 & 6,0 & 25,7 & 57,8 & 16,2 & 45,7 & 25,3 \\
\hline 2008 & 5,1 & 27,1 & 60,4 & 14,8 & 46,2 & 28,6 \\
\hline 2009 & 4,8 & 24,9 & 62,6 & 14,4 & 44,0 & 31,3 \\
\hline 2011 & 4,5 & 24,1 & 65,7 & 11,9 & 45,2 & 35,8 \\
\hline 2012 & 2,6 & 23,7 & 66,6 & 9,1 & 44,2 & 37,4 \\
\hline 2013 & 2,9 & 22,3 & 69,4 & 8,9 & 43,4 & 40,7 \\
\hline 2014 & 2,0 & 21,3 & 71,4 & 6,4 & 40,4 & 45,5 \\
\hline
\end{tabular}

Fonte: Instituto Brasileiro de Geografia e Estatística (2016a).

Apesar de haver um crescimento da distribuição da escolarização entre as raças, ainda é encontrada uma disparidade nessa faixa de idade, ainda que menos significativa. Em 2004 a proporção de adultos negros ainda matriculados na educação fundamental era de 23,6\% contra 8,7\% dos brancos (14,9 pp). Essa diferença, em 2014 passou a ser de 4,4 pp. É necessária uma continuidade nos esforços de redução das disparidades.

Conforme pode ser visualizado nessa tabela, comparando os períodos de tempo, os brancos tinham, em 2004, uma distribuição de escolaridade onde: $47,2 \%$ estavam no ensino superior, $31,4 \%$ no médio e $8,7 \%$ no ensino fundamental. Em 2014 a distribuição mostrava que $71,4 \%$ estavam no superior, $21,3 \%$ no médio e $2 \%$ no fundamental. Esses resultados apontam para uma melhoria significativa na escolarização dessa raça. Com relação aos pretos e pardos os dados mostram que, em 2004, a distribuição de escolaridade foi de $16,7 \%$ no ensino superior, $47,3 \%$ no médio e $23,6 \%$ no fundamental. Em 2014 a distribuição mostrava que 45,5\% estavam no superior, 40,4\% no médio e

Inclusive as pessoas de cor ou raça amarela e indígena. 
$6,4 \%$ no fundamental. Esses resultados apontam para uma melhoria bem significativa na escolarização dessa raça.

Considerando apenas o percentual no ensino superior os pretos e pardos em 2014 atingem patamares que os brancos possuíam anteriores a 2004, o que os coloca em mais de uma década de atraso nesse aspecto. Por outro lado, houve um grande acréscimo do percentual nesse nível de ensino entre pretos e pardos que era de $16,7 \%$ em 2004 e atinge 45,5\% em 2014, com um acréscimo de 28,8 pp.

Em função dos resultados dos indicadores apresentados até aqui a maior dificuldade das políticas de acesso se relaciona a possibilidade de reduzir as disparidades existentes entre os segmentos pesquisados, principalmente entre classes menos favorecidas economicamente e regionalmente. Outro ponto também a destacar é a alta taxa de retenção dos alunos uma vez que estão no ensino médio quando deveriam estar no superior.

A tabela 6, apresenta dados comparativos entre os sistemas de ensino público e particular, em todos os níveis de ensino, apenas considerando as classes de rendimento médio mensal das famílias dos estudantes.

\begin{tabular}{|c|c|c|c|c|c|}
\hline \multirow{2}{*}{ Estudantes } & \multicolumn{5}{|c|}{ Quintos de rendimento mensal familiar percentual per capita } \\
\hline & $1^{\circ}$ Quinto & $2^{\circ}$ Quinto & $3^{\circ}$ Quinto & $4^{0}$ Quinto & $5^{\circ}$ Quinto \\
\hline \multicolumn{6}{|c|}{ Fundamental } \\
\hline Pública & 40,8 & 27,6 & 16,8 & 10,8 & 4,0 \\
\hline Particular & 9,3 & 14,0 & 16,8 & 21,3 & 38,6 \\
\hline \multicolumn{6}{|c|}{ Médio } \\
\hline Pública & 25,8 & 26,5 & 21,7 & 18,3 & 7,7 \\
\hline Particular & 4,4 & 9,1 & 17,7 & 23,1 & 45,8 \\
\hline \multicolumn{6}{|c|}{ Superior } \\
\hline Pública & 7,6 & 12,7 & 18,0 & 25,3 & 36,4 \\
\hline Particular & 3,4 & 10,3 & 15,9 & 29,6 & 40,9 \\
\hline
\end{tabular}

Fonte: Instituto Brasileiro de Geografia e Estatística (2016a).

Tais dados mostram realidades diferentes por níveis de ensino. No ensino fundamental há uma inversão do acesso, ou seja, quanto mais baixos os rendimentos familiares, maiores as concentrações de estudantes em instituições públicas. Os dados da tabela indicam que conforme aumentam os níveis de renda média familiar, diminuem a proporção de matriculados. No ensino médio aumenta a proporção de concentração de estudantes em instituições particulares, comparativamente ao nível de ensino anterior.

No ensino superior, diferentemente dos anteriores, as classes mais altas se concentram em instituições particulares. Por outro lado, estudantes de classes mais baixas se encontram em instituições particulares. Este fenômeno indica um caminho natural da educação brasileira. A educação superior privada tem aumentado sua participação no total de estudantes. Considerando o período 2004-2014, a quantidade de matrículas na educação superior privada passou de $72 \%$ em 2004 para $75 \%$ em 2014. Em 2017 chega a 75,3\%, um aumento que tem determinado uma concentração de estudantes nesse tipo de instituição.

Na tabela 7 são apresentadas as proporções de pessoas na faixa etária de 18 a 24 anos, com menos de 11 anos de estudo, por renda e regionais do Brasil. Os dados mostram a proporção de estudantes fora do sistema educacional, na faixa etária de 18 a 24 anos, no ano de 2014. 
Tabela 7 - Proporção de pessoas de 18 a 24 anos de idade, com menos de 11 anos de estudo e que não frequentavam escola, por quintos de rendimento mensal domiciliar per capita nacional, segundo as Grandes Regiões - 2014.

\begin{tabular}{|c|c|c|c|c|c|c|}
\hline \multirow{3}{*}{ Grandes Regiões } & \multicolumn{6}{|c|}{ Proporção de pessoas de 18 a 24 anos de idade, com menos de 11 anos de estudo e que não frequentavam escola (\%) } \\
\hline & \multirow{2}{*}{ Total $^{8}$} & \multicolumn{5}{|c|}{ Quintos de rendimento mensal domiciliar per capita nacional } \\
\hline & & $1^{0}$ quinto & $2^{0}$ quinto & $3^{0}$ quinto & $4^{0}$ quinto & $5^{0}$ quinto \\
\hline Brasil & 31,2 & 52,2 & 41,5 & 31,9 & 20,8 & 9,0 \\
\hline Norte & 34,1 & 49,3 & 37,4 & 28,0 & 20,1 & 9,9 \\
\hline Nordeste & 36,3 & 50,8 & 39,9 & 27,2 & 17,7 & 7,3 \\
\hline Sudeste & 26,5 & 53,7 & 41,3 & 30,8 & 18,1 & 7,8 \\
\hline Sul & 33,0 & 66,7 & 53,4 & 43,7 & 27,4 & 12,4 \\
\hline Centro-Oeste & 30,5 & 54,5 & 41,9 & 37,9 & 26,4 & 9,7 \\
\hline
\end{tabular}

Fonte: Instituto Brasileiro de Geografia e Estatística (2016a).

Os dados evidenciam diferenças regionais. A diferença do indicador apresentado entre estudantes da região Nordeste e Sudeste é de 9,8 pp. Entre os mais pobres a diferença entre as regiões Sul e Norte representa 17,4 pp. Além das diferenças entre raças e renda familiares também são acentuadas as diferenças regionais.

A tabela 8 apresenta os resultados do indicador média de anos de estudo, em 2014, das pessoas de 25 anos ou mais, segmentadas por região e outras características selecionadas.

Tabela 8 - Média de anos de estudo das pessoas de 25 anos ou mais de idade, com indicação do coeficiente de variação, segundo as Grandes Regiões e algumas características selecionadas - 2014

\begin{tabular}{|c|c|c|}
\hline \multirow{2}{*}{ Grandes Regiões e algumas características selecionadas } & \multicolumn{2}{|c|}{ Média de anos de estudo das pessoas de 25 anos ou mais de idade } \\
\hline & Média & $\mathrm{CV}^{9}(\%)$ \\
\hline Brasi & 7,8 & 0,3 \\
\hline Norte & 7,3 & 0,8 \\
\hline Nordeste & 6,4 & 0,8 \\
\hline Sudeste & 8,5 & 0,5 \\
\hline Sul & 8,1 & 0,8 \\
\hline Centro-Oeste & 8,1 & 0,9 \\
\hline Sexo & & \\
\hline Homem & 7,6 & 0,4 \\
\hline Mulher & 8,0 & 0,3 \\
\hline Cor ou raça ${ }^{10}$ & & \\
\hline Branca & 8,7 & 0,4 \\
\hline Preta ou parda & 6,9 & 0,4 \\
\hline Quintos de rendimento mensal domiciliar per capita naciona & & \\
\hline $1^{\circ}$ quinto & 5,5 & 0,7 \\
\hline $2^{\circ}$ quinto & 6,3 & 0,5 \\
\hline $3^{\circ}$ quinto & 6,4 & 0,5 \\
\hline $4^{\circ}$ quinto & 8,0 & 0,4 \\
\hline $5^{\circ}$ quinto & 10,8 & 0,3 \\
\hline
\end{tabular}

Com relação à média de anos de estudo entre pessoas com 25 anos ou mais, no ano de 2014, o Brasil apresenta diferença entre brancos e pretos de 1,8 anos, em média. Enquanto brancos chegam ao ingresso no ensino médio, ainda que incompleto, pretos não conseguem ter a educação básica completa.

Considerando as classes de rendimento as diferenças são mais acentuadas. A diferença entre os mais ricos e os mais pobres é de 5,3 anos. Os mais pobres chegam a metade da formação da educação básica e os mais ricos quase ao final do ensino médio, sempre considerando que são médias. Com relação ao coeficiente de correlação, que revela a variabilidade do comportamento dos dados não foram encontrados resultados muito acentuados, onde existe maior diferença de valores foi na região centro-oeste, o que indica uma maior diferença entre o menor e o maior valor. 
No último indicador, apresentado na tabela 9, temos as taxas de analfabetismo de pessoas com 15 anos ou mais, em 2014, segmentadas por regiões e demais características selecionadas. de variação, segundo as Grandes Regiões e algumas características selecionadas - 2014

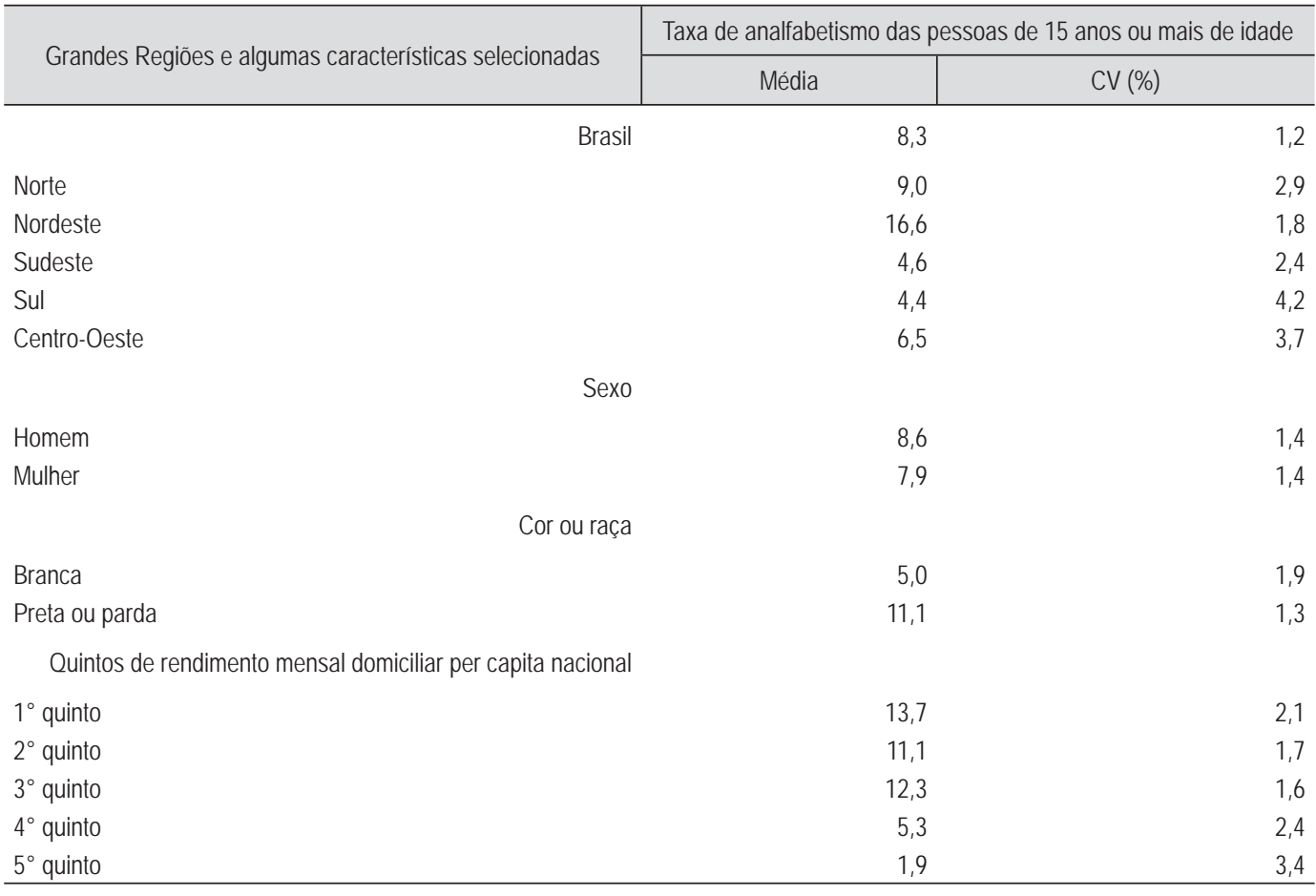

Fonte: Instituto Brasileiro de Geografia e Estatística (2016a).

Além das diferenças encontradas para as médias os coeficientes de variação também se mostram diferenciados. Com relação as médias as maiores diferenças encontradas são com relação as regiões Nordeste e Sul, representando 12,2 pp. Assim como entre os mais pobres e os mais ricos com 11,8 pp. Por outro lado, a variabilidade relativa mostra que há uma alta diferença entre os dados na região Sul. Ou seja, apesar de a taxa ser baixa ela esconde diferenças dentro da própria região.

Os ganhos nos resultados dos indicadores pesquisados ocorreram principalmente com relação as desigualdades de raça, regionais e de classes de rendimento familiar. Em praticamente todos os indicadores houve melhora nos resultados no período 20042014. A variabilidade dos dados é maior neste indicador do que o anterior.

\section{CONSIDERAÇÕES FINAIS}

Ainda que muitas políticas públicas no campo educacional tenham sido implantadas no período pesquisado, dois aspectos precisam ser considerados. Para algumas políticas, o efeito no resultado dos indicadores aparece em médio ou longo prazo. Certas políticas priorizaram o acesso à educação, sendo, de certa maneira, eficientes analisando-se o resultado de alguns de seus indicadores; contudo, a evasão escolar acaba desconstruindo a possibilidade de redução dos dados de desigualdade social, pois ainda que se amplie o acesso, as taxas de conclusão mostram a saída dos estudantes, principalmente aqueles que têm características de fragilidade social como pretos e pardos, classes sociais mais desfavorecidas ou oriundos de regiões menos desenvolvidas economicamente.

Em função disso, apontamos para a persistência das desigualdades brasileiras, conservando e reproduzindo processos socialmente excludentes para grande parte da população. As disparidades expressam a persistência de desigualdades profundas presentes na sociedade brasileira, "que não podem ser tomadas como 'fatores' isolados, mas como partes de uma totalidade histórica e contraditória" (FRIGOTTO, 2009, p. 17). 
Legislações, políticas e programas elaborados enquanto estratégias de reforma educacional, situações em que a educação não é interpretada como direito social, mas fundamentalmente articulada a políticas econômicas e de controle da pobreza, impactam em alguns avanços. Porém, como os dados analisados demonstram,distanciam-se das possibilidades reais de superação ou redução das desigualdades.

Frente ao exposto, as desigualdades tendem a continuar e podem se agravar colocando em risco os avanços identificados, principalmente pela ausência de legitimidade e não cumprimento do Plano Nacional de Educação e pela fragilização da concepção de um Sistema Nacional de Educação ou Regime de Colaboração. O Estado brasileiro historicamente apresenta uma perspectiva para a Educação de não garantia de continuidade de políticas e programas desenvolvidos e implantados em governos anteriores.

\section{REFERÊNCIAS}

AKKARI, A. Internacionalização das Políticas Educacionais: transformações e desafios. Petrópolis: Vozes, 2011.

ARROYO, M. G. Políticas educacionais, igualdades e diferenças. Revista Brasileira de Política e Administração da Educação, v. 27, n. 1, p. 83-94, jan./abr. 2011.

BALL, S. J. Educação Global S.A.: novas redes políticas e o imaginário neoliberal. Ponta Grossa: UEPG, 2014.

BRASIL. Constituição da República Federativa do Brasil de 1988. Diário Oficial da União, Brasília, DF, 5 out. 1988. Disponível em: <https://www.planalto.gov.br/ccivil_03/constituicao/constituicao.htm>. Acesso em: 25 ago. 2017.

Emenda Constitucional $n^{0} 59$, de 11 de novembro de 2009. Acrescenta $\S 3^{\circ}$ ao art. 76 do Ato das Disposições Constitucionais Transitórias para reduzir, anualmente, a partir do exercício de 2009, o percentual da Desvinculação das Receitas da União incidente sobre os recursos destinados à manutenção e desenvolvimento do ensino de que trata 0 art. 212 da Constituição Federal. Diário Oficial da União, Brasília, DF, 12 nov. 2009. Disponível em: <http://www.planalto.gov.br/ccivil_03/constituicao/emendas/emc/emc59.htm>. Acesso em: 25 ago. 2017.

Lei $n^{0}$ 9.394, de 20 de dezembro de 1996. Estabelece as diretrizes e bases da educação nacional. Diário Oficial da União, Brasília, DF, 23 dez. 1996a.

Disponível em: <http://www.planalto.gov.br/ccivil_03/leis//9394.htm>. Acesso em: 25 ago. 2017.

Lei $n^{0}$ 9.424, de 24 de dezembro de 1996. Dispõe sobre o Fundo de Manutenção e Desenvolvimento do Ensino Fundamental e de Valorização do Magistério. Diário Oficial da União, Brasília, DF, 26 dez. 1996b. Disponível em: <http://www.planalto.gov.br/ccivil_03/leis/L9424.htm >. Acesso em: 25 ago. 2017.

Lei $n^{0}$ 10.836, de 9 de janeiro de 2004. Cria o Programa Bolsa Família e dá outras providências. Diário Oficial da União, Brasília, DF, 12 jan. 2004. Disponível em: <http://www.planalto.gov.br/ccivil_03/_ato20042006/2004/lei//10.836.htm>. Acesso em 25 ago. 2017.

Lei no 11.494, de 20 de junho de 2007. Regulamenta o Fundo de Manutenção e Desenvolvimento da Educação Básica e de Valorização dos Profissionais da Educação - FUNDEB. Diário Oficial da União, Brasília, DF, 21 jun. 2007. Disponível em: <http://www.planalto.gov.br/ccivil_03/_ato2007-2010/2007/lei//11494.htm>. Acesso em: 25 ago. 2017.

Lei $n^{0}$ 12.711, de 29 de agosto de 2012. Dispõe sobre 0 ingresso nas universidades federais e nas instituições federais de ensino técnico de nível médio e dá outras providências. Diário Oficial da União, Brasília, DF, 30 ago. 2012. Disponível em: 〈http://www.planalto.gov.br/ccivil_03/_ato2011-2014/2012/lei//12711.htm>. Acesso em: 25 ago. 2017. 
. Lei no 13.005, de 25 de junho de 2014. Aprova o Plano Nacional de Educação - PNE e dá outras providências. Diário Oficial da União, Brasília, DF, 26 jun. 2014. Disponível em: <http://www.planalto.gov.br/ ccivil_03/_ato2011-2014/2014/lei/l13005.htm>. Acesso em: 25 ago. 2017.

- Ministério da Educação. Secretaria de Articulação com os Sistemas de Ensino. Instituir um Sistema Nacional de Educação: agenda obrigatória para o país. Brasília, DF: MEC; SASE, 2015. Disponível em: <http://pne. mec.gov.br/images/pdf/SNE_junho_2015.pdf>. Acesso em 18 jun. 2015.

CAMPOS, Maria Malta. Educação e políticas de combate à pobreza. Revista Brasileira de Educação, n. 24, p. 183191, 2003.

CONAE 2010. Conferência Nacional de Educação: documento-referência. Construindo o Sistema Nacional Articulado de Educação: o Plano Nacional de Educação, diretrizes e estratégias de ação. Brasília, DF: MEC; SEA, 2009. Disponível em: <http://portal.mec.gov.br/arquivos/pdf/conae/documento_referencia.pdf>. Acessoem: 20 ago. 2017.

CONAE 2014: Conferência Nacional de Educação: documento-referência. O PNE na articulação do Sistema Nacional de Educação: participação popular, cooperação federativa e regime de colaboração. Brasília, DF: MEC; SEA, [2013]. Disponível em: <http://conae2014.mec.gov.br/images/pdf/doc_referencia.pdf>. Acesso em: 25 ago. 2017.

DUBET, F. As desigualdades multiplicadas. ljuí: Unijuí, 2003.

FERREIRA, H.; CASSIOLATO, M.; GONZALEZ, R. Uma experiência de desenvolvimento metodológico para avaliação de programas: 0 modelo lógico do programa segundo tempo. Brasília, DF: IPEA, 2009. Texto para discussão $n^{0}$ 1369. Disponível em: <http://www.ipea.gov.br/portal/index.php?option=com_content\&view\%20 =article\&id=4921\%3A\%20td-1369-uma-experiencia-de-desenvolvimento-metodologico-para-avaliacao-de-programas-omodelo-logico-do-programa-segundo-tempo\&catid=\%20272\%3A2009\&directory=1\&ltemid=1>. Acesso em: 25 ago. 2017.

FRIGOTTO, G. Prefácio. In: ALGEBAILE, E. Escola Pública e pobreza no Brasil: a ampliação para menos. Rio de Janeiro: Lamparina; FAPERJ, 2009.

FRITSCH, R.; VITELLI, R. F.; ROCHA, C. S. Defasagem idade-série em Escolas Estaduais de Ensino Médio do Rio Grande do Sul. Revista Brasileira de Estudos Pedagógicos, Brasília, v. 95, n. 239, p. 218-236, jan./abr. 2014.

INSTITUTO BRASILEIRO DE GEOGRAFIA E ESTATÍSTICA. A Instituição. Rio de Janeiro, [199-]. Disponível em: <http://www.ibge.gov.br/home/disseminacao/eventos/missao/default.shtm>. Acesso em: 6 jun. 2017.

. Pesquisa Nacional por Amostra de Domicílios 2004-2014. Rio de janeiro, 2016a. Disponível em: <https:ll sidra.ibge.gov.br/pesquisa/pnad>. Acesso em: 25 ago. 2017.

Resultados de pesquisa. Rio de Janeiro, 2016b. Disponível em: <http://www.ibge.gov.br/home/ estatistica/pesquisas/pesquisa_resultados.php?id_pesquisa=149>. Acesso em: 6 jun. 2017.

JANNUZZI, P. de M. Indicadores sociais no Brasil: conceitos, fontes de dados e aplicações. 4. ed. Campinas-SP: Editora Alínea, 2009.

- Indicadores sociais na formulação e avaliação de políticas públicas. 2011. CEDEPS - Educação, Cidadania

e Desenvolvimento Profissional. Disponível em: <http://www.cedeps.com.br/wp-content/uploads/2011/02/ INDICADORES-SOCIAIS-JANUZZI.pdf>. Acesso em: 22 abr. 2017.

- Indicadores para avaliação sistêmica de programas sociais: 0 caso Pronatec . Estudos em Avaliação Educacional, São Paulo, v. 27, n. 66, p. 624-661, set./dez. 2016.

MINAYO, M. C. de S. Construção de Indicadores Qualitativos para Avaliação de Mudanças. Revista Brasileira de Educação Médica, v. 33, n. 1, p. 83-91, 2009. Suplemento 1. 
OLIVEIRA, D. A. As políticas educacionais no governo Lula: rupturas e permanências. Revista Brasileira de Política e Administração da Educação, v. 25, n. 2, p. 197-209, maio/ago. 2009.

SAMPAIO, G. T. C.; OLIVEIRA, R. L. P. de. Dimensões da desigualdade educacional no Brasil. Revista Brasileira de Política e Administração da Educação, v. 31, n. 3, p. 511-530, set./dez. 2015.

SCAFF, E. A. da S.; FONSECA, M. (Org.). Gestão e Planejamento da Educação Básica nos cenários nacional e internacional. Campinas-SP: Mercado das Letras, 2016.

SOUZA, Marcelle. Brasil tem 2,8 milhões de crianças e adolescentes fora da escola. UOL, São Paulo, 19 jan. 2016. Educação. Disponível em: <https://educacao.uol.com.br/noticias/2016/01/19/brasil-tem-28-milhoes-de-criancas-eadolescentes-fora-da-escola.htm>. Acesso em: 30 jan. 2019.

SPOSATI, Aldaiza. Mínimos Sociais e Seguridade Social: Uma Revolução da Consciência da Cidadania. Serviço Social \& Sociedade, São Paulo, v. 55, p. 09-38, 1997.

TEODORO, A. A educação em tempos de globalização neoliberal: os novos modos de regulação das políticas educacionais. Brasília-DF: Liber Livro, 2011.

\section{(Footnotes)}

1 Para essa informação não havia disponível os dados referentes aos anos de 2004 a 2006. Em 2010, há o recenseamento, por esse motivo não acontece a PNAD.

2 Exclusive as pessoas de cor ou raça amarela e indígena.

3 Taxa de conclusão do ensino fundamental: proporção de pessoas com idade de 3 a 5 anos acima da idade esperada de frequência no último ano do ensino fundamental (de 17 a 19 anos de idade) que concluíram esse nível.

4 Exclusive as pessoas de cor ou raça amarela e indígena.

5 Taxa de conclusão do ensino médio: proporção de pessoas com idade de 3 a 5 anos acima da idade esperada de frequência no último ano do ensino fundamental (de 20 a 22 anos de idade) que concluíram esse nível.

6 Exclusive as pessoas de cor ou raça amarela e indígena.

7 Inclui Mestrado e Doutorado.

8 Inclusive pessoas sem declaração de rendimento domiciliar per capita.

9 CV é o coeficiente de variação dos dados. Ele indica a variabilidade relativa entre os valores.

10 Exclusive as pessoas de cor ou raça amarela e indígena. 